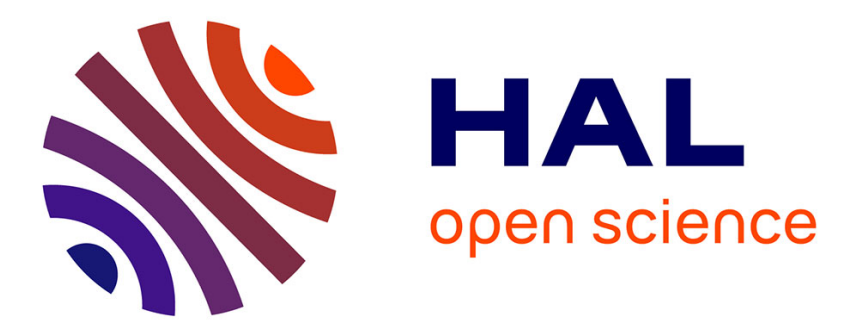

\title{
A Dual Targeting Dendrimer-Mediated siRNA Delivery System for Effective Gene Silencing in Cancer Therapy
}

Yiwen Dong, Tianzhu Yu, Ling Ding, Erik Laurini, Yuanyu Huang, Mengjie

Zhang, Yuhua Weng, Shuting Lin, Peng Chen, Domenico Marson, et al.

\section{- To cite this version:}

Yiwen Dong, Tianzhu Yu, Ling Ding, Erik Laurini, Yuanyu Huang, et al.. A Dual Targeting Dendrimer-Mediated siRNA Delivery System for Effective Gene Silencing in Cancer Therapy. Journal of the American Chemical Society, 2018, 140 (47), pp.16264-16274. 10.1021/jacs.8b10021 . hal02992903v1

\section{HAL Id: hal-02992903 \\ https://hal.science/hal-02992903v1}

Submitted on 6 Nov 2020 (v1), last revised 2 Dec 2020 (v2)

HAL is a multi-disciplinary open access archive for the deposit and dissemination of scientific research documents, whether they are published or not. The documents may come from teaching and research institutions in France or abroad, or from public or private research centers.
L'archive ouverte pluridisciplinaire HAL, est destinée au dépôt et à la diffusion de documents scientifiques de niveau recherche, publiés ou non, émanant des établissements d'enseignement et de recherche français ou étrangers, des laboratoires publics ou privés. 


\title{
A Dual Targeting Dendrimer-Mediated siRNA Delivery System for Effective Gene Silencing in Cancer Therapy
}

\author{
Yiwen Dong, ${ }^{\dagger}$ Tianzhu Yu, ${ }^{\ddagger}$ Ling Ding, ${ }^{\ddagger}$ Erik Laurini, ${ }^{\S_{\odot}}$ Yuanyu Huang, ${ }^{\|, \perp \odot ~ M e n g j i e ~ Z h a n g, ~}$ \\ Yuhua Weng, \\ Sabrina Pricl, ${ }^{\S}$ Xiaoxuan Liu, ${ }^{*},+$, Palma Rocchi, $^{\#}$ and Ling Peng ${ }^{*},+0$
}

${ }^{\dagger}$ State Key Laboratory of Natural Medicines and Jiangsu Key Laboratory of Drug Discovery for Metabolic Diseases, Center of Drug Discovery, Center of Advanced Pharmaceutics and Biomaterials, China Pharmaceutical University, 24 Tong Jia Xiang, 210009 Nanjing, People's Republic of China

${ }^{\ddagger}$ Aix-Marseille Université, CNRS, Centre Interdisciplinaire de Nanoscience de Marseille, UMR 7325, “Equipe Labellisée Ligue Contre le Cancer", 13288 Marseille, France

${ }^{\S}$ Molecular Biology and Nanotechnology Laboratory (MolBNL@UniTS), DEA, University of Trieste, 34127 Trieste, Italy

"Advanced Research Institute of Multidisciplinary Science and School of Life Science, Beijing Institute of Technology, Beijing 100081, People's Republic of China

${ }^{\perp}$ School of Pharmacy, Hunan University of Chinese Medicine, Changsha 410208, People’s Republic of China

\#Inserm, Aix-Marseille Université, Institut Paoli-Calmettes, CNRS, CRCM, 13009 Marseille, France

\section{Supporting Information}

ABSTRACT: Small interfering RNA (siRNA) is emerging as a novel therapeutic for treating various diseases, provided a safe and efficient delivery is available. In particular, specific delivery to target cells is critical for achieving high therapeutic efficacy while reducing toxicity. Amphiphilic dendrimers are emerging as novel promising carriers for siRNA delivery by virtue of the combined multivalent cooperativity of dendrimers with the self-assembling property of lipid vectors. Here, we report a ballistic approach for targeted siRNA delivery to cancer cells using an amphiphilic dendrimer equipped with a dual targeting peptide bearing an RGDK warhead. According to the molecular design, the amphiphilic dendrimer was expected to deliver siRNA effectively, while the

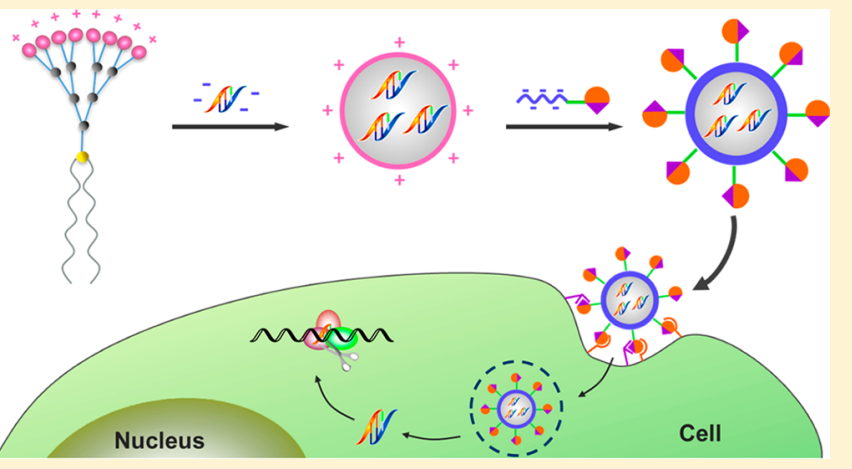
aim of the targeting peptide was to home in on tumors via interaction of its warhead with integrin and the neuropilin-1 receptor on cancer cells. Coating the positively charged siRNA/dendrimer delivery complex with the negatively charged segment of the targeting peptide via electrostatic interactions led to small and stable nanoparticles which were able to protect siRNA from degradation while maintaining the accessibility of RGDK for targeting cancer cells and preserving the ability of the siRNA to escape from endosomes. The targeted system had enhanced siRNA delivery, stronger gene silencing, and more potent anticancer activity compared to nontargeted or covalent dendrimer-based systems. In addition, neither acute toxicity nor induced inflammation was observed. Consequently, this delivery system constitutes a promising nonviral vector for targeted delivery and can be further developed to provide RNAi-based personalized medicine against cancer. Our study also gives new perspectives on the use of nanotechnology based on self-assembling dendrimers in various biomedical applications.

\section{INTRODUCTION}

Gene therapy based on RNA interference (RNAi), a posttranscriptional gene silencing phenomenon triggered by small interfering RNA (siRNA), ${ }^{1,2}$ is emerging as a promising therapeutic option for treating various diseases. ${ }^{3-5}$ Particularly exciting is the first ever RNAi-based gene-silencing siRNA drug "patisiran", which was approved by the FDA this year. ${ }^{6}$ As siRNA targets and breaks down the corresponding mRNA via Watson-Crick base-pairing, in principle it can be harnessed to target any gene with known sequence, in particular, disease- associated genes for therapeutic purposes. ${ }^{3-5}$ However, naked siRNA is not a stable therapeutic agent per se, as it can be rapidly degraded by enzymes such as nucleases or esterases, which pervade body fluids. In addition, siRNA molecules are hydrophilic and highly negatively charged and, hence, cannot readily cross cell membranes to reach the RNAi machinery in the cytosol for gene silencing. Moreover, if administered at

Received: September 15, 2018

Published: October 22, 2018 
high concentration, naked siRNA will often generate off-target effects, which can induce severe adverse effects. Consequently, there is a high demand for safe and effective siRNA delivery systems that are able to protect the nucleic acid from degradation, deliver it to the target cells, and ultimately promote functional gene silencing. ${ }^{7-10}$

Both viral and nonviral delivery vectors have been explored for siRNA delivery. Although viral delivery is more effective, increasing concerns over the immunogenicity and toxicity of viral vectors urge the development and improvement of synthetic carrier systems. ${ }^{7-10}$ Lipids and polymers are the most commonly applied nonviral vectors for siRNA delivery. ${ }^{11-15}$ Dendrimers, a special family of polymers, have emerged as promising siRNA carriers by virtue of their well-defined structural architecture, cooperative multivalence, and intriguing ability to carry a high cargo payload within a nanosized volume. ${ }^{16-20}$ We have recently developed a series of cationic amphiphilic dendrimers ${ }^{21-24}$ that couple the multivalent cooperativity of dendrimer vectors with the self-assembling property of lipid vectors, hence capitalizing on the advantageous characteristics of both lipid and dendrimer vectors for effective delivery. ${ }^{25,26}$ One of these multivalent self-assembling dendrimers, AD (Scheme 1A), exhibits particularly high performance for siRNA delivery to a wide range of cell types, including highly challenging human primary cells and stem cells. ${ }^{22}$ Importantly, AD is also able to deliver siRNA to tumors in xenograft mice for successful in vivo gene silencing and potent anticancer activity. ${ }^{22}$

With the aim of further improving the AD-mediated siRNA delivery, we wanted to endow $\mathrm{AD}$ with an active targeting ability for specific delivery to cancer cells within tumor lesions. In principle, active targeting can be realized by introducing a targeting moiety on the delivery system, which can interact with and bind to ligands or receptors present on the cell surface. $^{27,28}$ In this way, the therapeutic cargo can be delivered specifically to the target cells, thereby achieving higher therapeutic efficacy while sparing other cells to reduce toxicity. Different targeting agents such as antibodies, peptides, and small molecular ligands have been applied to construct active targeting systems. ${ }^{27-31}$ Among them, the RGDK peptide is particularly appealing for cancer targeting because it has dual targeting capacity within a short peptide segment. ${ }^{32}$ On one hand, RGD can target tumor endothelium by interacting with $\alpha_{\nu} \beta_{3}$ integrin, which is overexpressed in tumor vasculature; ${ }^{33,34}$ on the other hand, RGDK is able to bind to the neuropilin-1 (Nrp-1) receptor, which is present on tumor cells, hence promoting cancer cell penetration and uptake. ${ }^{32,35}$ In a previous study, we were able to demonstrate the validity of this dual targeting strategy for siRNA delivery and enhanced performance in gene silencing using a poly(amidoamine) PAMAM dendrimer of generation $5\left(\mathrm{G}_{5}\right)$ that was decorated with the same targeting peptide. ${ }^{36}$ However, producing a large quantity of pure, high-generation PAMAM dendrimers requires considerable cost, time, and effort. ${ }^{37,38}$ Accordingly, in this paper we report the introduction of the dual targeting warhead RGDK to the small amphiphilic dendrimer AD-based delivery system (Scheme 1), which effectively led to targeted siRNA delivery and enhanced gene silencing compared to the nontargeting system. In contrast to our former study, ${ }^{36}$ in the present effort we exploit the quintessence of nanotechnology, i.e., the controlled self-assembly of small, synthetically amenable building blocks to generate a nanosystem for siRNA delivery. We further demonstrate that decoration of
Scheme 1. Strategy for Active Delivery of siRNA Using an Amphiphilic Dendrimer AD Vector with the Dual Targeting Peptide: (A) Chemical Structure of the Amphiphilic Dendrimer AD; (B) The Targeting Peptide $\mathrm{E}_{16} \mathrm{G}_{6}$ RGDK Composed of Three Distinct Functional Segments: RGDK as the Targeting Warhead, Oligo(glutamic acid) $E_{16}$ as the Negatively Charged Sequence to Interact with Positively Charged siRNA/AD Complexes, and the Neutral Oligo(glycine) $G_{6}$ as the Linker to Bridge the Targeting Unit and the siRNA Loading Complex; (C) Cartoon Illustration of the Formation of the siRNA/AD/ $E_{16} G_{6} R G D K$ Complexes for Targeted siRNA Delivery
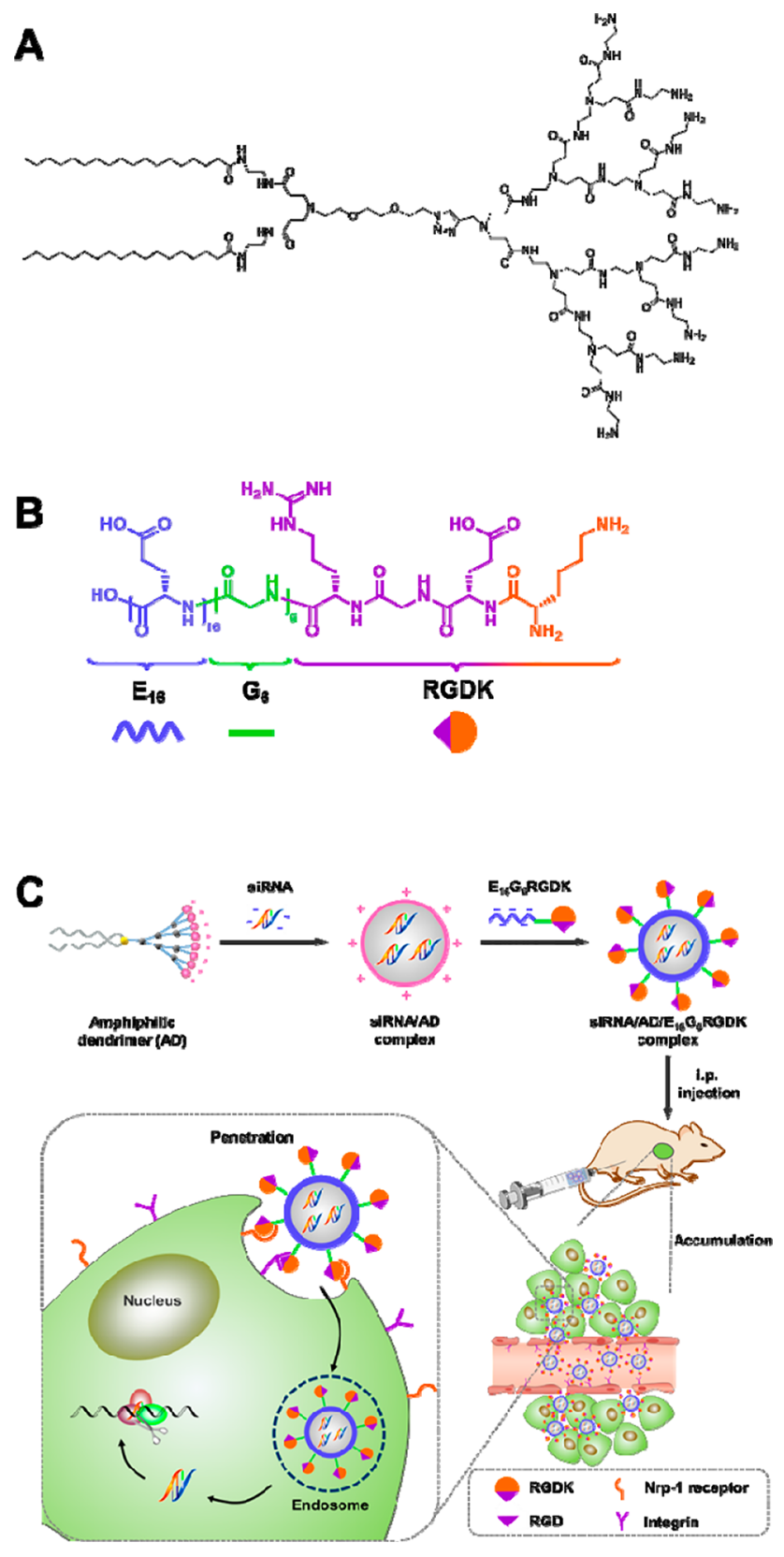

the resulting siRNA/AD system with this dual targeting peptide not only is feasible but, most importantly, leads to in vitro and in vivo results substantially superior to those achieved with the covalent high-generation dendrimer decorated with the same peptide. This is the first report to explore a targeting 
A

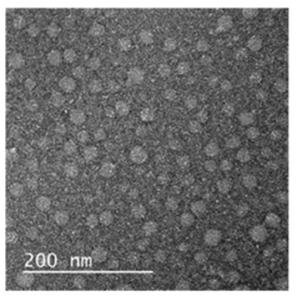

B

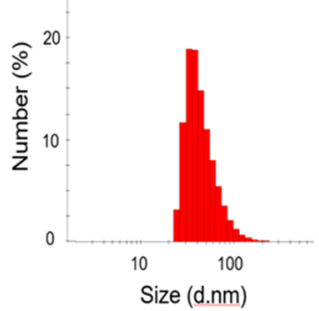

C

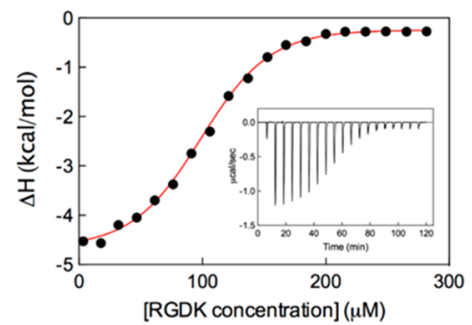

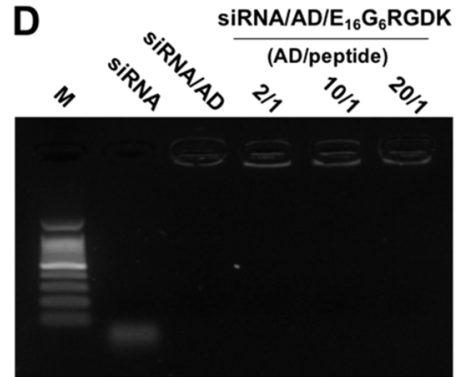

$\mathbf{E}$

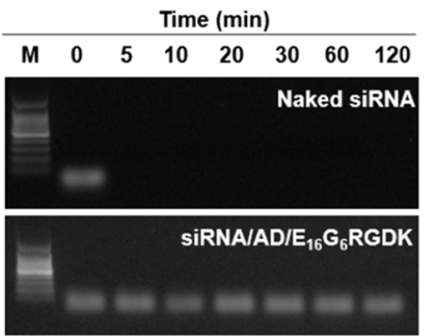

Figure 1. Small and stable siRNA/AD/ $E_{16} G_{6} R G D K$ complexes formed by adding the peptide $\mathrm{E}_{16} \mathrm{G}_{6} \mathrm{RGDK}$ to the siRNA/AD complexes. (A) TEM imaging and (B) DLS analysis of the siRNA/AD/ $\mathrm{E}_{16} \mathrm{G}_{6} \mathrm{RGDK}$ complexes (siRNA/AD at an N/P ratio of 10, AD/peptide at a molar ratio of 5.0). (C) Representative integrated ITC profiles for titration of the siRNA/AD complexes with the $\mathrm{E}_{16} \mathrm{G}_{6} \mathrm{RGDK}$ peptide in ultrapure water $\left(T=25^{\circ} \mathrm{C}\right)$. The solid red lines are data fitted with a sigmoidal function. The inset shows the corresponding ITC raw data. All experiments were run in triplicate. (D) Agarose gel shift analysis of the siRNA/AD/ $\mathrm{E}_{16} \mathrm{G}_{6} \mathrm{RGDK}$ complexes versus the siRNA/AD complexes (siRNA/AD at an N/P ratio of $10, \mathrm{AD} /$ peptide ratio varying from 2.0 to 20). (E) The siRNA/AD/ $\mathrm{E}_{16} \mathrm{G}_{6} \mathrm{RGDK}$ complexes are able to protect siRNA from RNase A digestion. (siRNA/ $\mathrm{AD}$ at an $\mathrm{N} / \mathrm{P}$ ratio of $10 ; \mathrm{AD} /$ peptide ratio of 5.0 ).

strategy for self-assembling dendrimer-mediated siRNA delivery.

In our strategy to append the RGDK targeting moiety on the AD-based delivery system, we used the peptide $\mathrm{E}_{16} \mathrm{G}_{6} \mathrm{RGDK}$, which is composed of three distinct functional segments: (1) the targeting unit RGDK, (2) the negatively charged oligo(glutamic acid) $\mathrm{E}_{16}$, and (3) the neutral oligo(glycine) $\mathrm{G}_{6}$ (Scheme 1B). The RGDK segment will mediate the dual active targeting function by homing to the tumor vasculature via $\mathrm{RGD}$ /integrin binding and, at the same time, targeting cancer cells via binding of RGDK to Nrp-1 receptors on the cell surface. The negatively charged oligo(glutamic acid) segment $\mathrm{E}_{16}$ will serve to promote the attachment of the targeting peptide to the positively charged siRNA/AD complex via electrostatic interaction. ${ }^{36,39}$ The neutral oligo(glycine) segment $\mathrm{G}_{6}$ will act as the linker to connect the targeting warhead RGDK to the siRNA/AD delivery complexes (Scheme 1C). To prove the concept of this targeting delivery, we used PC-3 prostate cancer cells as the cancer model, because PC-3 cells have highly overexpressed integrin and Nrp-1 receptors on the surface. ${ }^{30,40}$

Prostate cancer ( $\mathrm{PCa}$ ) has the highest incidence rate and is the major cause of cancer-related deaths in males in Western countries. $^{41}$ Although androgen deprivation therapy is beneficial as the standard first-line treatment in early stage hormone-naive $\mathrm{PCa}$, castration-resistant prostate cancer (CRPC) unfortunately often develops within one or two years. $^{42,43}$ CRPC is associated with poor prognosis, high apoptosis resistance, and high mortality, ${ }^{44}$ and no efficacious treatment for managing CRPC is clinically available to date. ${ }^{43}$ Recently, we demonstrated that using AD-mediated siRNA delivery to target the cancer cell survival gene Hsp27, which encodes heat shock protein $27,{ }^{45-47}$ is an effective approach for treating CRPC. ${ }^{22}$ In this study, we provide further proof that the AD-based delivery system equipped with the RGDK targeting peptide is much more effective than the nontargeted one and superior to the covalent $G_{5}$ PAMAM dendrimer decorated with the same peptide for siRNA delivery and gene silencing of $\mathrm{Hsp} 27,^{36}$ ultimately leading to more potent anticancer activity in CRPC models in vitro and in vivo. The superior delivery efficiency can be ascribed to the active dual targeting mechanism via RGD/integrin and RGDK/Nrp-1 receptor interactions in addition to the excellent delivery performance of the amphiphilic dendrimer AD. Therefore, this study demonstrates that the strategy to coat the amphiphilic dendrimer-based siRNA delivery system with the dual targeting RGDK warhead constitutes a powerful approach to achieve effective and specific tumor targeting for more efficient siRNA delivery and potent gene silencing. This approach can be further developed for RNAi-based personalized medicine in fighting cancer.

\section{RESULTS AND DISCUSSION}

Formation of Small and Stable Peptide-Decorated siRNA/AD/ $E_{16} \mathrm{G}_{6}$ RGDK Complexes. For effective siRNA delivery, it is important that the delivery system is small and stable. This is because small nanoparticulate complexes can penetrate deep into tumor tissue and be taken up efficiently by cancer cells, and stable delivery complexes effectively protect the siRNA against enzyme degradation. In our system, by simply adding the targeting peptide $\mathrm{E}_{16} \mathrm{G}_{6} \mathrm{RGDK}$ to the siRNA/AD complex in solution, small and spherical nanoparticles were formed, as illustrated by the results obtained using transmission electron microscopy (TEM) (Figure 1A) 

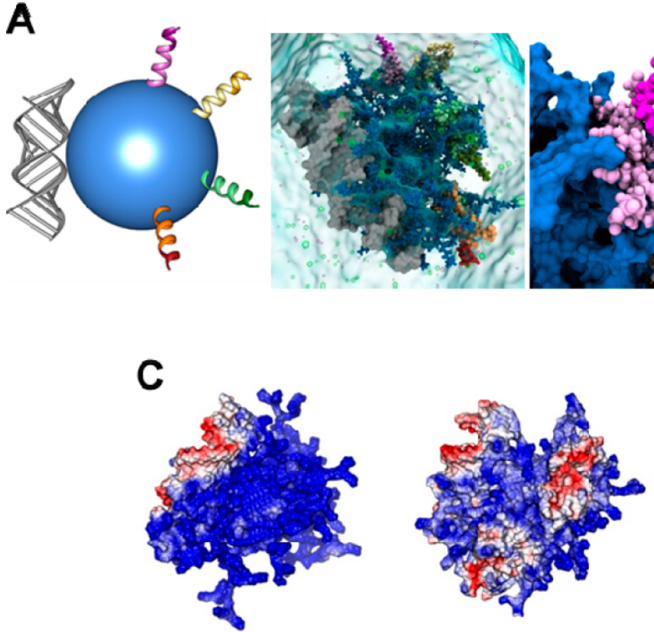

B

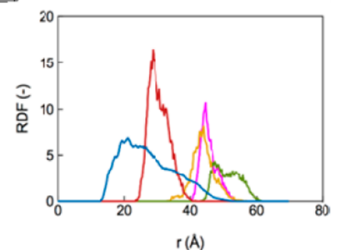

$r(A)$

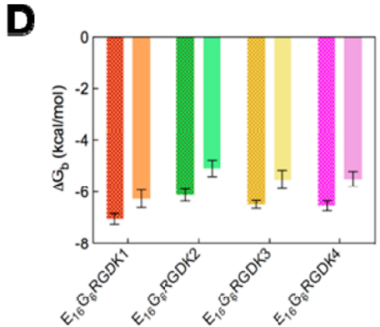

Figure 2. (A) (Left) Cartoon showing the arrangement of the siRNA molecule (gray) and the four $\mathrm{E}_{16} \mathrm{G}_{6} \mathrm{RGDK}$ moieties (colored as in the right panel) on the $\mathrm{AD}$ nanomicelle (blue), as derived from the detailed atomistic molecular simulations. (Center) Equilibrated molecular dynamics (MD) snapshot of an siRNA/AD micelle in complex with four $\mathrm{E}_{16} \mathrm{G}_{6}$ RGDK peptides numbered as $\mathrm{E}_{16} \mathrm{G}_{6} \mathrm{RGDK} 1$ to $\mathrm{E}_{16} \mathrm{G}_{6} \mathrm{RGDK}$ and colored as follows: $E_{16} G_{6} R G D K 1$, tail $\left(E_{16} G_{6}\right)$ sandy brown, head (RGDK) firebrick; $E_{16} G_{6} R G D K 2$, tail light green, head olive drab; $E_{16} G_{6} R G D K 3$, tail khaki, head golden rod; $\mathrm{E}_{16} \mathrm{G}_{6} \mathrm{RGDK} 4$, tail plum, head magenta. The siRNA molecule is portrayed with its van der Waals surface in gray. The $\mathrm{AD}$ micelle is shown in dark slate blue sticks and balls, while the four peptides are depicted as colored spheres, as above precised. Ions and counterions are shown as green and purple hollow spheres; water is shown as a light cyan surface. (Right) Zoomed-in view of the system in panel A showing the RGDK warhead group of $\mathrm{E}_{16} \mathrm{G}_{6} \mathrm{RGDK} 4$ protruding into the solvent as an example. (B) Radial distribution function as a function of the distance from the $\mathrm{AD}$ micelle center of mass for the $\mathrm{AD}$ positively charged terminal groups (dark slate blue) and for each of the four RGDK warhead groups. Colors as in panel A. (C) Electrostatic surface potential of the siRNA/AD micelle (left) and of the siRNA/AD/( $\left.\mathrm{E}_{16} \mathrm{G}_{6} \mathrm{RGDK}\right)_{4}$ complex (right) as extracted from the equilibrated portion of the corresponding MD simulations. Dark blue represents a highly positively charged surface, while red represents a highly negatively charged surface. (D) Free energy of binding $\left(\Delta G_{\mathrm{b}}\right)$ of each $\mathrm{E}_{16} \mathrm{G}_{6} \mathrm{RGDK}$ peptide on the siRNA/AD micelle. Colors as in panel A. The empty color bars (left bar of each pair) represent the value of $\Delta G_{b}$ for the entire peptide molecule, while the filled color bars (right bar of each pair) give the contribution to $\Delta G_{\mathrm{b}}$ from the negatively charged $\mathrm{E}_{16} \mathrm{G}_{6}$ tails only.

and dynamic light scattering (DLS) analysis (Figure 1B). The dimensions of the peptide-decorated siRNA/AD/ $\mathrm{E}_{16} \mathrm{G}_{6} \mathrm{RGDK}$ complexes are around $30-45 \mathrm{~nm}$, which are in the size range required for effective cellular uptake. In addition, the zeta potential of the siRNA/AD/ $\mathrm{E}_{16} \mathrm{G}_{6} \mathrm{RGDK}$ nanoparticles is +15 $\mathrm{mV}$, which is lower than the noncoated siRNA/AD complexes $(+32 \mathrm{mV})$. This finding indicates that the negatively charged $\mathrm{E}_{16} \mathrm{G}_{6} \mathrm{RGDK}$ peptide indeed bound to the positively charged siRNA/AD complexes as expected, hence decreasing the positive surface charge.

We further assessed the binding thermodynamics of the $\mathrm{E}_{16} \mathrm{G}_{6} \mathrm{RGDK}$ peptides to the siRNA/AD complexes by carrying out isothermal titration calorimetry (ITC) measurements. The binding process is mainly characterized by a favorable enthalpic contribution $(\Delta \mathrm{H}=-5.0 \pm 0.2 \mathrm{kcal} / \mathrm{mol})$, as testified by the exothermic peaks of the corresponding thermogram (Figure 1C). A small favorable entropy change is also estimated $(-T \Delta S=-1.9 \mathrm{kcal} / \mathrm{mol})$, and, accordingly, the overall complex formation is thermodynamically favored, with a free energy of binding $(\Delta G)$ value of $-6.8 \mathrm{kcal} / \mathrm{mol}$. The substantial enthalpic nature of the binding supports the fact that the electrostatic forces play the leading role, while the positive entropic term can be reasonably ascribed to stabilizing peptide/complex hydrophobic interactions and water/ion release into the bulk solvent.

We next studied the stability of the siRNA/AD/ $\mathrm{E}_{16} \mathrm{G}_{6} \mathrm{RGDK}$ complexes using gel mobility shift assays in the presence of RNase. As shown in Figure 1D, adding the peptide $\mathrm{E}_{16} \mathrm{G}_{6} \mathrm{RGDK}$ to the siRNA/AD complexes at different peptide/AD ratios did not cause any siRNA release, high- lighting the formation of stable siRNA/AD/ $\mathrm{E}_{16} \mathrm{G}_{6} \mathrm{RGDK}$ complexes and complete encapsulation of siRNA. Further experiments with RNase treatment demonstrate that the siRNA/AD/ $/ \mathrm{E}_{16} \mathrm{G}_{6} \mathrm{RGDK}$ complexes effectively protected siRNA from enzymatic digestion, whereas free siRNA was not stable and was degraded rapidly within $5.0 \mathrm{~min}$ (Figure 1E). Collectively, our results show that the peptide-coated siRNA/AD/ $/ \mathrm{E}_{16} \mathrm{G}_{6} \mathrm{RGDK}$ complexes are small and stable and are able to protect siRNA from degradation. All these are important and beneficial features for effective siRNA delivery.

Accessible RGDK Targeting Moieties in the Stable Peptide-Coated Complexes. To get further insight into the peptide-coated siRNA/AD/ $\mathrm{E}_{16} \mathrm{G}_{6} \mathrm{RGDK}$ complexes at the molecular level, we performed atomistic molecular dynamics (MD) simulations as we did in our previous work. ${ }^{21,48}$ As can be seen in Figure 2A, a stable $(1.0 \mu \mathrm{s})$ Janus-like nanoparticle was formed, in which four $\mathrm{E}_{16} \mathrm{G}_{6}$ RGDK peptides are adsorbed onto the siRNA/AD assembly, with the nucleic acids on the opposite side. From the same figure, it is evident that, as initially surmised, the negative tails of the peptides $\left(\mathrm{E}_{16}\right)$ are in close contact with the positive charges of the PAMAM dendron heads of $\mathrm{AD}$ and, most importantly, the RGDK warhead groups protrude well into the solvent (Figure 2A). This qualitative observation is quantitatively supported by the results in Figure $2 \mathrm{~B}$, which shows the radial distribution function (RDF) for the positively charged terminals of the $A D$ molecules and the RGDK terminals of the four $E_{16} G_{6}$ RGDK peptides. These curves clearly indicate that the RDGK moieties are located away from the nanoparticle periphery, thus being available for interaction with the cellular receptors. Finally, the 
A

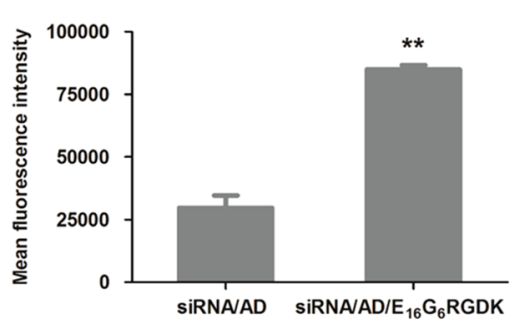

C
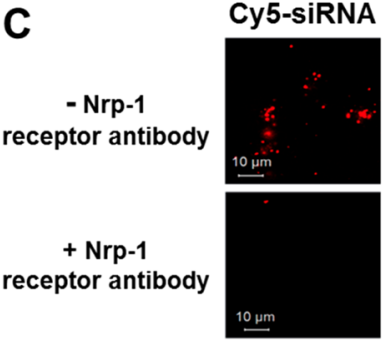

\section{B}
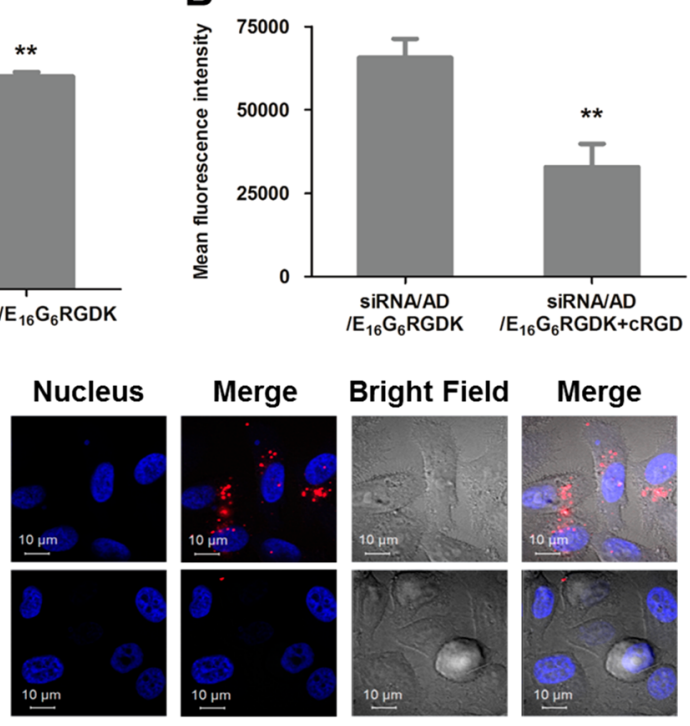

Cy5-siRNA Endosome

Merge
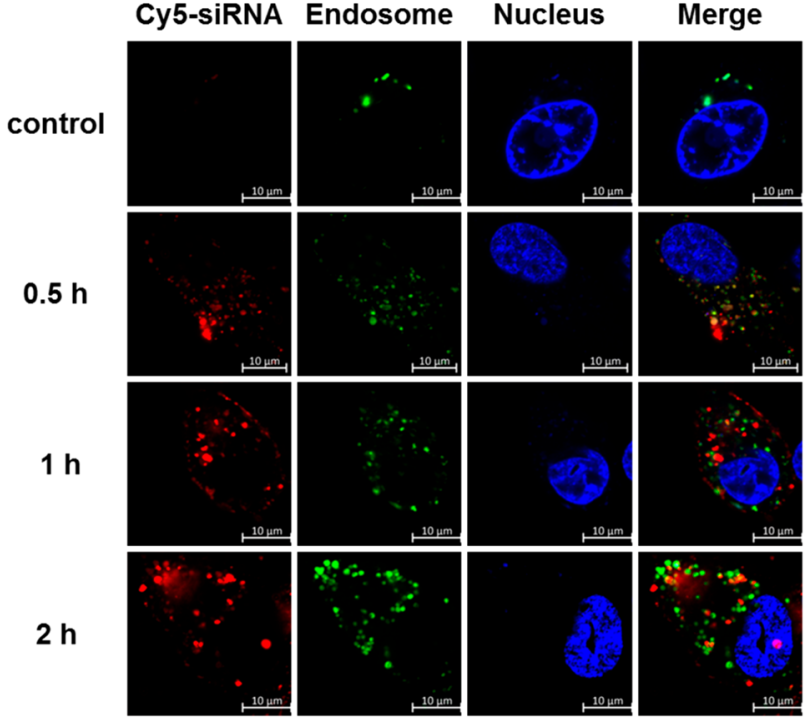

Figure 3. SiRNA/AD/ $\mathrm{E}_{16} \mathrm{G}_{6} \mathrm{RGDK}$ complexes are effectively taken up by PC-3 prostate cancer cells via RGD/integrin and RGDK/neuropilin-1 (Nrp-1) receptor interactions and are then released from endosomes. (A) Flow cytometry analysis of the cellular uptake of siRNA/AD/ $\mathrm{E}_{16} \mathrm{G}_{6} \mathrm{RGDK}$ complexes compared to siRNA/AD complexes using Cy5-labeled siRNA. (B) Flow cytometry analysis of the cellular uptake of siRNA/AD/ $\mathrm{E}_{16} \mathrm{G}_{6}$ RGDK complexes in the absence and presence of cyclic RGD (cRGD). (C) Confocal microscopic imaging of the cellular uptake of siRNA/AD/ $\mathrm{E}_{16} \mathrm{G}_{6} \mathrm{RGDK}$ complexes in the absence and presence of Nrp-1-receptor antibody. (D) Confocal microscopic imaging of the endosomal escape of the siRNA/AD/ $\mathrm{E}_{16} \mathrm{G}_{6} \mathrm{RGDK}$ complexes after incubation times of 0 (control), 0.5, 1.0, and 2.0 h. Red channel image shows the Cy5-labeled siRNA/AD/ $\mathrm{E}_{16} \mathrm{G}_{6} \mathrm{RGDK}$ complexes, green channel image shows the endosomes marked by LysoTracker red, and blue channel image shows the nuclei of PC-3 cells stained by DAPI (C) or Hoechst 33342 (D). The siRNA/AD/ $\mathrm{E}_{16} \mathrm{G}_{6} \mathrm{RGDK}$ complexes were formed using 50 $\mathrm{nM}$ siRNA, an N/P ratio of 10, and $\mathrm{AD} /$ peptide molar ratio of 5.0. Data are presented as mean \pm SD. $* *, p \leq 0.01$ as calculated by Student's $t$ test.

targeting peptides are compared in Figure 2C. In agreement with the experimentally determined zeta-potentials, binding of the negatively charged peptides on the surface of the siRNA/ $\mathrm{AD}$ complex results in a lower positive electrostatic surface compared to the undecorated siRNA/AD binary assembly.

To estimate the intensity of the interaction between each peptide and the siRNA/AD complex, the MD data were further processed using the MM/PBSA approach. ${ }^{49-51}$ The free energy of binding $\left(\Delta G_{\mathrm{b}}\right)$ between each of the four $\mathrm{E}_{16} \mathrm{G}_{6} \mathrm{RGDK}$ peptides and the siRNA/AD complex is shown in Figure $2 \mathrm{D}$. All peptides are characterized by a favorable (i.e., negative) $\Delta G_{\mathrm{b}}$ value (in the range $-7.0 \pm 0.2$ to $-6.1 \pm 0.2$ $\mathrm{kcal} / \mathrm{mol}$, empty bars in Figure 2D). The major contribution to binding is the strong electrostatic interaction between the negatively charged peptide tails $\left(\mathrm{E}_{16}\right)$ and the protonated amines at the AD terminals (filled bars in Figure 2D). Altogether, our molecular simulation results further support our initial molecular concept and hypothesis that the $\mathrm{E}_{16} \mathrm{G}_{6} \mathrm{RGDK}$ peptides form stable complexes with siRNA/ $\mathrm{AD}$, ultimately yielding nanoparticles with a lower positive surface charge while leaving the RGDK warheads available for cellular receptor interactions. All the simulation data are in line with our experimental results.

Enhanced Cell Uptake via Dual Receptor-Mediated Interactions Followed by Effective Endosomal Escape. Our aim in decorating the siRNA/AD delivery complex with 
A
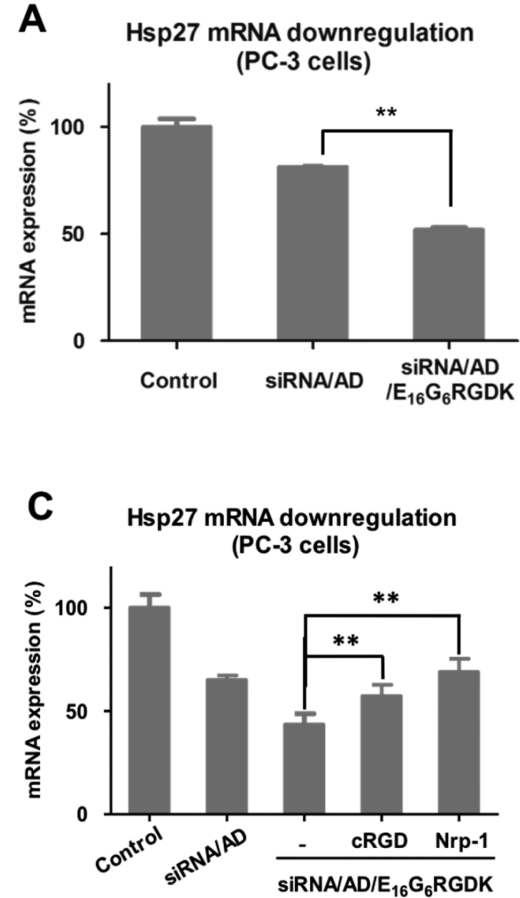

B Hsp27 protein downregulation (PC-3 cells)

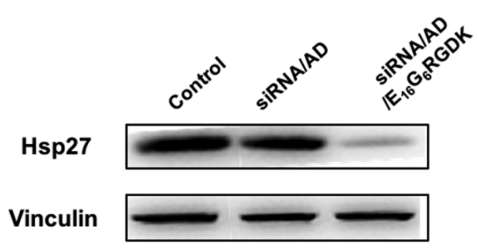

D MTT assay (PC-3 cells)

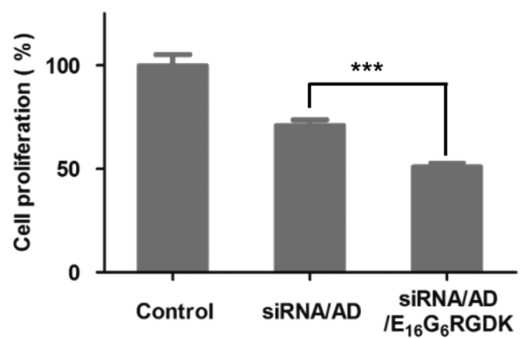

Figure 4. Targeted siRNA/AD/ $\mathrm{E}_{16} \mathrm{G}_{6} \mathrm{RGDK}$ system is much more effective than the nontargeted siRNA/AD system for Hsp27 silencing and antiproliferation in PC-3 prostate cancer cells. Hsp27 silencing at (A) mRNA and (B) protein levels, determined using qRT-PCR and Western blotting, respectively. (C) The improved down-regulation of Hsp27 at the mRNA level by the targeting complexes is reduced in the presence of either cRGD or anti-Nrp-1-receptor antibody. (D) MTT assay of the antiproliferation effect of the complexes on PC-3 cells. Conditions used: 20 $\mathrm{nM}$ siRNA, $\mathrm{N} / \mathrm{P}$ ratio of $10, \mathrm{AD} /$ peptide molar ratio of 5.0. Data are presented as mean $\pm \mathrm{SD}$. $* *, p \leq 0.01$; $* * *, p \leq 0.001$ as calculated by Student's $t$ test.

the dual targeting peptide $\mathrm{E}_{16} \mathrm{G}_{6} \mathrm{RGDK}$ was to improve the delivery efficiency and specificity by actively targeting cancer cells via both RGD/integrin binding and RGDK/Nrp-1 interaction while also ensuring effective endosomal escape. We therefore first investigated the uptake of the peptidedecorated complexes by PC-3 prostate cancer cells, which are characterized by high expression of both integrin and Nrp-1 receptors. ${ }^{30,40}$ Using siRNA labeled with the fluorescent dye $\mathrm{Cy} 5$, we found that the internalization of the peptide-coated Cy5-siRNA/AD/ $\mathrm{E}_{16} \mathrm{G}_{6} \mathrm{RGDK}$ complexes was significantly (3.0-fold) higher than the noncoated Cy5-siRNA/AD complexes in PC-3 cells (Figure 3A). In addition, the uptake of the peptide-decorated Cy5-siRNA/AD/ $\mathrm{E}_{16} \mathrm{G}_{6} \mathrm{RGDK}$ complexes was considerably reduced in the presence of cyclic RGD (cRGD) (Figure 3B), indicating that cRGD competed with the peptide-coated nanoparticles for integrin binding. This confirms that the peptide-decorated delivery complexes indeed bound to integrin via the RGD motif. Also, as shown by confocal microscopic imaging in Figure 3C, cells pretreated with anti-Nrp-1-receptor monoclonal antibody had dramatically reduced internalization of the Cy5-siRNA/AD/ $\mathrm{E}_{16} \mathrm{G}_{6} \mathrm{RGDK}$ complexes compared to untreated cells. This highlights that the peptide-decorated complexes are effectively taken up by cells via RGDK/Nrp-1 receptor interaction. Collectively, these results provide evidence that the cellular uptake of the peptide-coated siRNA/dendrimer complexes was indeed mediated by RGD/integrin and RGDK/Nrp-1 receptor interactions, and the uptake of the decorated complexes by PC-3 cells was more efficient than the nondecorated ones.

After cellular uptake, it is important that the peptidedecorated delivery complexes are able to escape from the endosomes and release siRNA for subsequent gene silencing.
We therefore further examined the endosomal escape of the fluorescent Cy5-siRNA/AD/ $\mathrm{E}_{16} \mathrm{G}_{6} \mathrm{RGDK}$ complexes in the presence of LysoTracker, which fluorescently labels acidic compartments. As we can see in the confocal microscopic images (Figure 3D), after $0.5 \mathrm{~h}$ of incubation the fluorescent signals from the LysoTracker and the Cy5 dye colocalized in sharp and clear-cut spots, implying that the Cy5-siRNA/AD/ $\mathrm{E}_{16} \mathrm{G}_{6} \mathrm{RGDK}$ complexes were entrapped in the endosomes. Notably, after $1.0 \mathrm{~h}$ of incubation, dispersed and smeared Cy5 fluorescent signals were observed, suggesting that the some of the Cy5-siRNA/AD/ $\mathrm{E}_{16} \mathrm{G}_{6} \mathrm{RGDK}$ complexes had escaped from the endosomes into the cytoplasm. After $2.0 \mathrm{~h}$, more of the Cy5 fluorescent signals were diffuse in the cytoplasm and there was less colocalization with the LysoTracker, indicating the successful escape of the Cy5-siRNA from the endosomes. Consequently, the peptide-decorated siRNA delivery complexes are able to circumvent endosome trapping and effectively release siRNA in the cytoplasm for subsequent gene silencing.

Targeted Delivery Increases Gene Silencing and Anticancer Activity in Vitro. We next compared the ability of the targeting peptide-decorated siRNA delivery complexes and the nondecorated ones to down-regulate Hsp27 in PC-3 prostate cancer cells. Using a low concentration $(20 \mathrm{nM})$ of siRNA targeting Hsp27, a small chaperone protein involved in cancer cell proliferation and drug resistance, the peptide-coated siRNA/AD/ $\mathrm{E}_{16} \mathrm{G}_{6} \mathrm{RGDK}$ complexes were significantly more effective than the noncoated siRNA/AD complexes at knocking down Hsp27 at the mRNA level (Figure 4A), leading to more than $90 \%$ inhibition of $\mathrm{Hsp} 27$ protein expression (Figure 4B). Of note, a significantly higher siRNA concentration $(50 \mathrm{nM})$ was necessary to produce comparable 
A

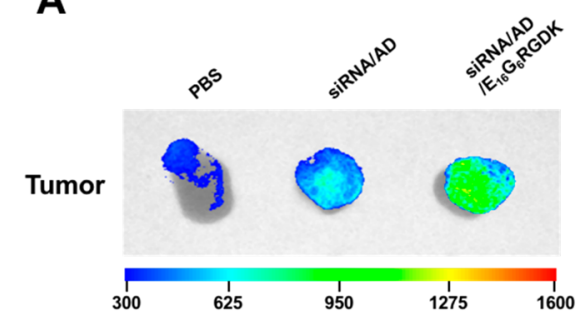

C

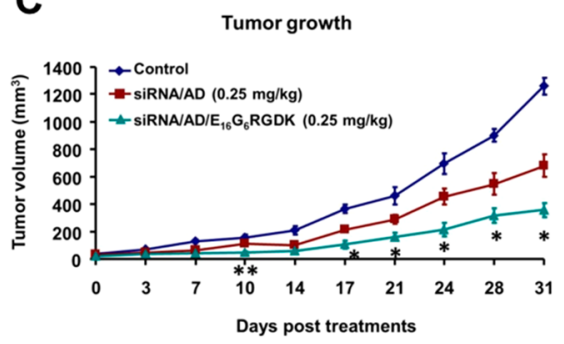

E

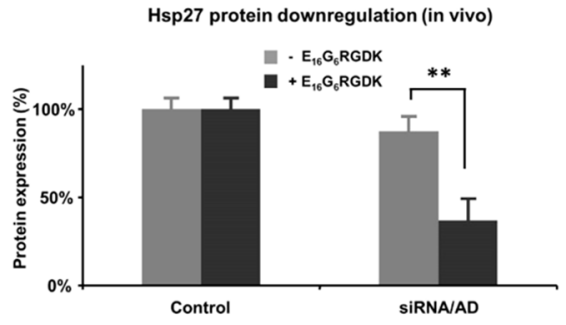

B

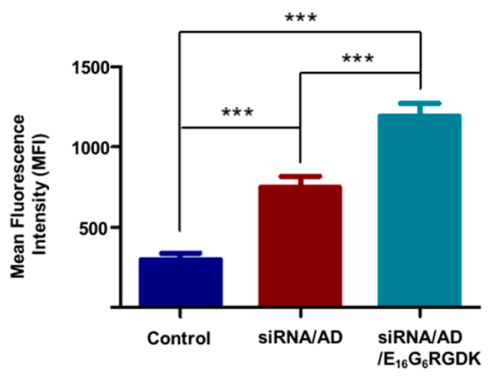

D

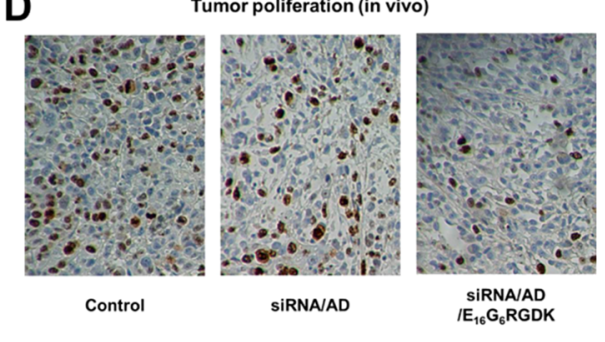

F

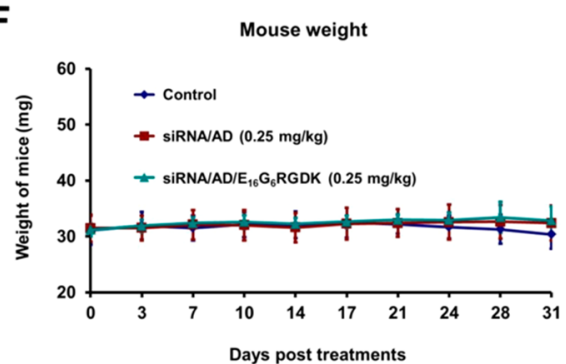

Figure 5. Targeted siRNA/AD/ $\mathrm{E}_{16} \mathrm{G}_{6} \mathrm{RGDK}$ delivery system (A, B) accumulates more efficiently in tumor tissues and (C, D) is much more potent than the nontargeted siRNA/AD system for gene silencing and anticancer activity in tumor xenograft mice. Cy5-siRNA/AD complexes and Cy5siRNA/AD/ $\mathrm{E}_{16} \mathrm{G}_{6} \mathrm{RGDK}$ complexes were administered to PC-3 xenograft mice via i.v. injection in PBS buffer (1.0 mg/kg siRNA, N/P ratio 5.0, $\mathrm{AD}$ /peptide molar ratio 5). (A) Fluorescence images of siRNAs accumulated in isolated tumors. (B) Fluorescence quantification analysis of tumors in (A) using imaging software. Data were normalized to the tumors from PBS-treated animals. PC-3 xenograft nude mice were administered twice per week with PBS buffer, siRNA/AD complexes, or siRNA/AD/ $\mathrm{E}_{16} \mathrm{G}_{6} \mathrm{RGDK}$ complexes $(0.25 \mathrm{mg} / \mathrm{kg}$ siRNA, N/P ratio 5.0, AD/peptide molar ratio 5). (C) Tumor growth assessed by measuring tumor size. (D) Cancer cell proliferation in tumor tissue revealed by immunohistochemistry using Ki67 staining. (E) Expression of Hsp27 protein in tumors quantified using Western blotting. (F) Mouse body weight monitoring during the treatment. Data are presented as mean $\pm \mathrm{SD}$. ${ }^{*}, p \leq 0.05 ; * *, p \leq 0.01$, ***, $p \leq 0.001$ as calculated by Student's $t$ test.

effects using the generation 5 PAMAM dendrimer decorated with the same peptide. ${ }^{36}$ This highlights that the peptidecoated delivery system effectively improved gene silencing. The enhanced down-regulation of Hsp27 by the targeting complexes was reduced in the presence of either cRGD or anti-Nrp-1-receptor antibody (Figure 4C), indicating that cRGD and anti-Nrp-1-receptor antibody competed with the peptide-coated nanoparticles for binding with integrin and Nrp-1 receptors, respectively. This again supports the view that the peptide-decorated delivery complexes indeed act via integrin- and Nrp-1 receptor-mediated targeting. Further assessment of in vitro anticancer activity using the MTT assay revealed that the peptide-decorated siRNA/AD/ $\mathrm{E}_{16} \mathrm{G}_{6} \mathrm{RGDK}$ complexes drastically reduced the proliferation of PC-3 cells with respect to the noncoated siRNA/AD complexes (Figure 4D). Collectively, our results demonstrate that actively targeted delivery via the peptide-coated nanosystem is indeed more effective for siRNA-mediated gene silencing of Hsp27 and leads to a more pronounced reduction in proliferation than the nontargeted delivery system.
Targeted Delivery Enhances Gene Silencing and Antitumor Activity in Vivo. To investigate the power of the targeting system for siRNA delivery in vivo, we used the PC-3 xenograft nude mouse model. We first assessed the tumor targeting capability of these formulations using fluorescent Cy5-labeled siRNA. Ex vivo imaging of isolated tumors showed that the targeting system siRNA/AD/ $\mathrm{E}_{16} \mathrm{G}_{6} \mathrm{RGDK}$ had significantly higher mean florescence intensity (MFI) in tumors than the nontargeting system siRNA/AD (Figure 5A and B). This result demonstrates that decoration with the targeting peptide indeed enhanced the tumor targeting capability of the amphiphilic dendrimer in vivo.

We further examined gene silencing and tumor growth inhibition with both targeting and nontargeting systems. The siRNA delivery complexes were administered twice per week for 4.0 weeks. It is worth mentioning that we applied a very low siRNA concentration of $0.25 \mathrm{mg} / \mathrm{kg}$ at an N/P ratio of 5 , which is more than 10 times lower than that used when performing the same experiments using the covalent $G_{5}$ PAMAM dendrimer, ${ }^{36}$ i.e., the conventional siRNA concentration used for in vivo siRNA delivery in mice $(3.0 \mathrm{mg} / \mathrm{kg})$. 

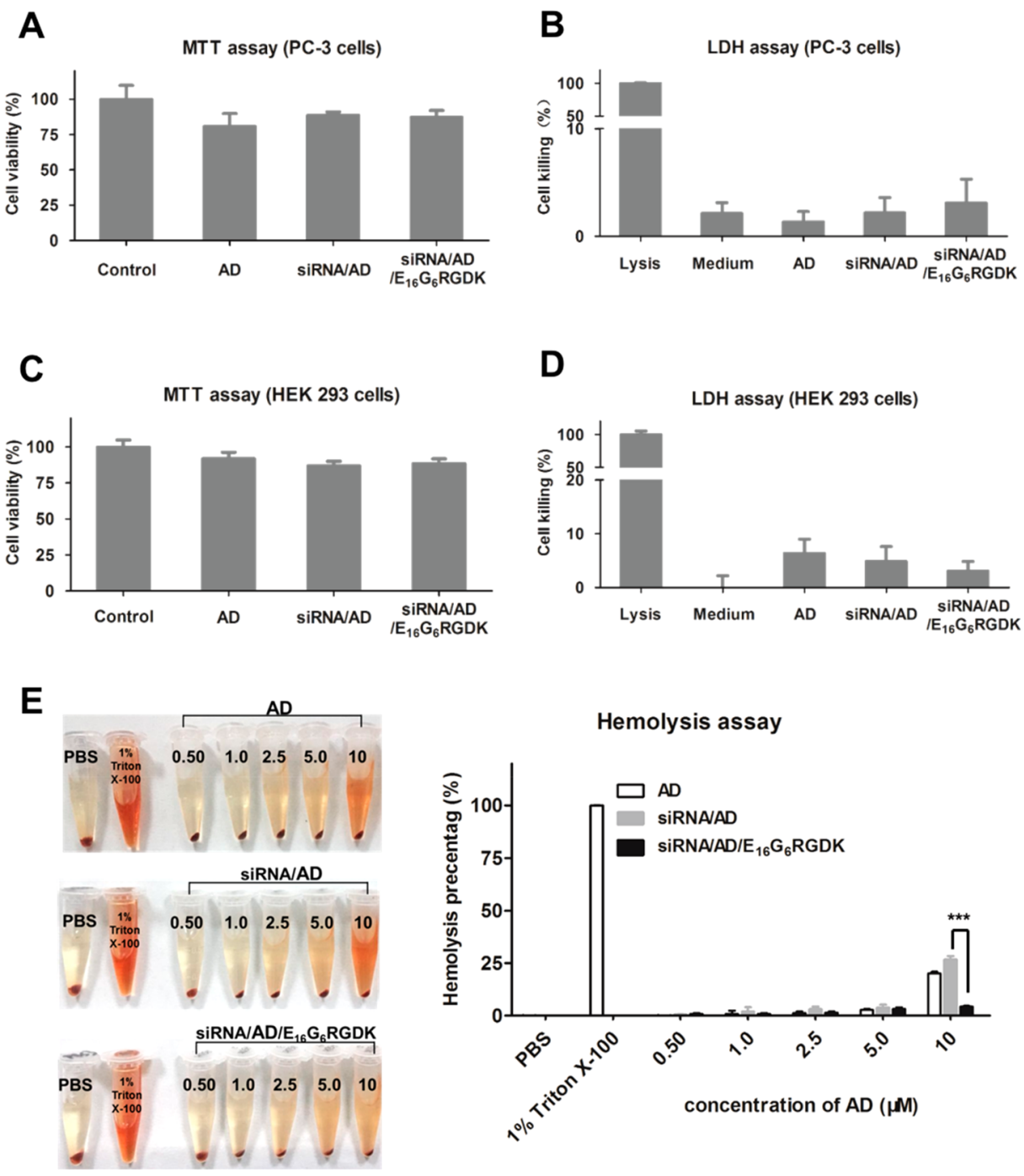

Figure 6. In vitro toxicity assessment of the targeted siRNA/AD/ $\mathrm{E}_{16} \mathrm{G}_{6} \mathrm{RGDK}$ delivery system versus the nontargeted siRNA/AD system. Toxicity assessment using the MTT assay and LDH assay for (A, B) PC-3 prostate cancer cells and (C, D) human embryonic kidney (HEK 293) cells (20 $\mathrm{nM}$ siRNA, N/P ratio of 10, AD/peptide molar ratio of 5.0). (E) Left panel: Hemolysis assay of the siRNA/AD complexes and the siRNA/AD/ $\mathrm{E}_{16} \mathrm{G}_{6} \mathrm{RGDK}$ complexes in comparison with $\mathrm{AD}$ alone at different concentrations of $\mathrm{AD}$ (0.50, 1.0, 2.5, 5.0, and $\left.10 \mu \mathrm{M}\right)$, which correspond to siRNA concentrations of 10, 20,50, 100, and $200 \mathrm{nM}$. Right panel: Quantitative analysis of hemolysis determined by UV absorption at $540 \mathrm{~nm}$. Data are presented as mean \pm SD. ${ }^{* * *}, p \leq 0.001$ as calculated by Student's $t$ test.

Remarkably, the targeted siRNA/AD/ $\mathrm{E}_{16} \mathrm{G}_{6} \mathrm{RGDK}$ delivery system reduced the tumor growth much more effectively than the nontargeted siRNA/AD system (Figure 5C). Also, immunohistochemistry (IHC) analysis revealed that cancer cell proliferation was inhibited more efficiently in tumors from mice treated with the targeted siRNA/AD/ $\mathrm{E}_{16} \mathrm{G}_{6} \mathrm{RGDK}$ complexes than in tumors from mice treated with nontargeted ones (Figure 5D). Further Western blotting analysis of the protein level of Hsp27 in tumor tissue (Figure 5E) confirmed that the silencing of $\mathrm{Hsp} 27$ was indeed more effective in mice treated with the targeted siRNA/AD/ $\mathrm{E}_{16} \mathrm{G}_{6} \mathrm{RGDK}$ delivery system than the nontargeted one. All these data demonstrate that the targeted delivery approach is more potent in gene silencing than nontargeted delivery, and hence more effective in inhibiting cancer cell proliferation and retarding tumor growth in PC-3 xenografts. In addition, there was no alteration of the body weights of the mice (Figure 5F), which highlights the promising safety profile of this delivery system. Altogether, these results provide strong evidence for enhanced siRNA delivery specifically to cancer cells using the amphiphilic dendrimer AD-based delivery system equipped with the dual targeting peptide.

The Targeted Delivery System Is Safe and Devoid of Toxicity. The superior delivery capacity of the targeted delivery system motivated us to further evaluate its toxicity profile for eventual therapeutic applications. We performed the MTT assay, which measures cell metabolic activity and provides an indication of metabolic toxicity, and the $\mathrm{LDH}$ assay, which determines the membrane integrity by quantifying the lactate dehydrogenase released from cells into the extracellular medium. Results from both MTT and LDH assays using a nontargeting scramble siRNA control revealed that neither metabolic toxicity nor membrane damage was induced in cancer cells (PC-3 cells) (Figure 6A and B) and noncancer cells (HEK cells) (Figure 6C and D) after treatment with the targeted siRNA/AD/ $\mathrm{E}_{16} \mathrm{G}_{6} \mathrm{RGDK}$ delivery system and the nontargeted one. Neither the targeted siRNA/AD/ $\mathrm{E}_{16} \mathrm{G}_{6} \mathrm{RGDK}$ nanoparticles nor the nontargeted siRNA/AD 

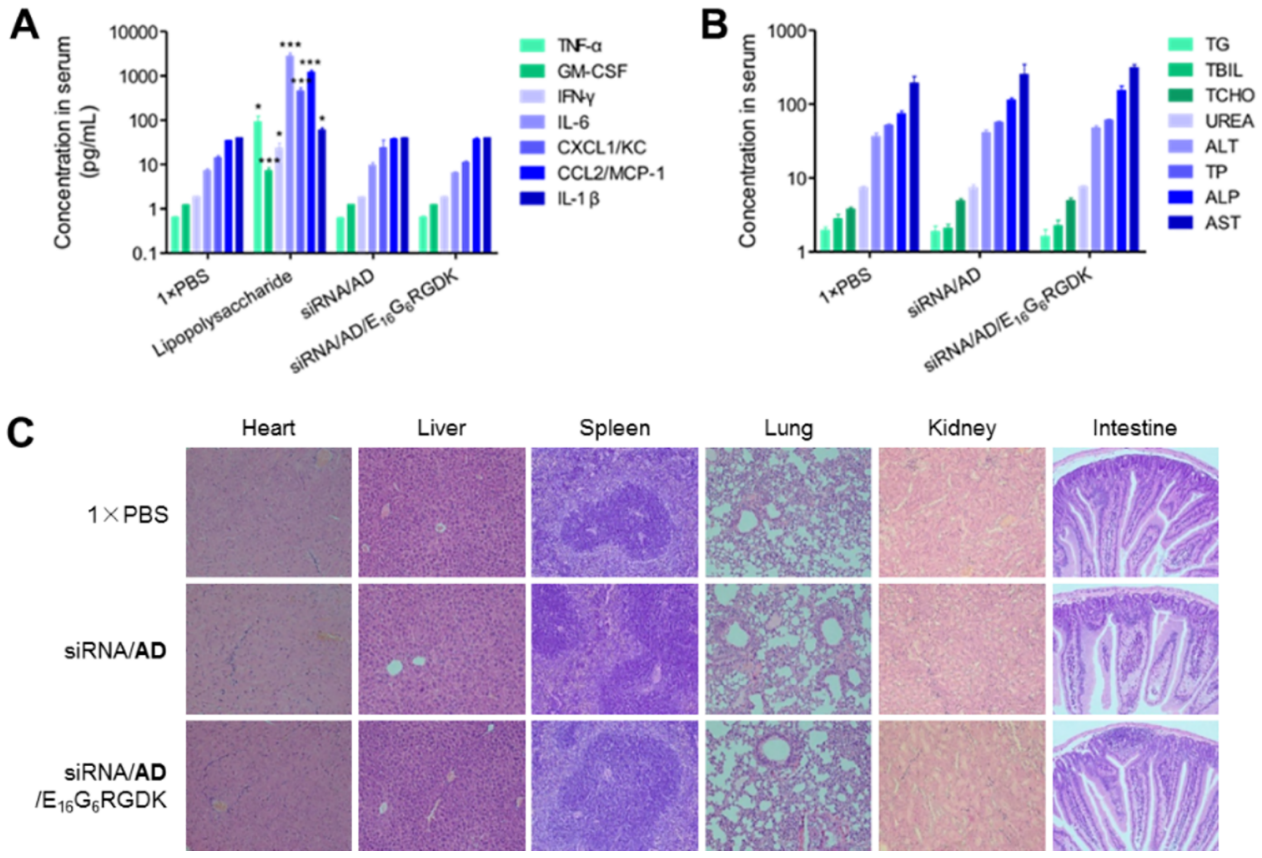

Figure 7. In vivo toxicity assessment of the targeted siRNA/AD/ $\mathrm{E}_{16} \mathrm{G}_{6} \mathrm{RGDK}$ delivery system versus the nontargeted siRNA/AD system. (A) Cytokine response in mice determined by quantifying the serum levels of IL-6, INF- $\gamma$, TNF- $\alpha$, GM-CSF, MCP-1, KC, and IL-1 $\beta$ at $3 \mathrm{~h}$ postinjection using Luminex-detection technology according to the manufacturer's protocol. Lipopolysaccharide (LPS) was used as the positive control. Data are presented as mean \pm SEM. $*, p<0.05$, ***, $p<0.001$, versus PBS group, as calculated by Student's $t$ test. (B) Major serum biochemistry parameters measured in mouse serum collected at $24 \mathrm{~h}$ postinjection. Alanine transaminase (ALT), aspartate transaminase (AST), and alkaline phosphatase (ALP) are measured as U/L; total bilirubin (TBIL), urea, triacylglycerol (TG), and total cholesterol (TCHO) are measured as $\mathrm{mmol} / \mathrm{L}$; total protein (TP) is measured as $\mathrm{g} / \mathrm{L}$. Data are shown as mean \pm SEM. (C) Histopathological analysis of major organs from mice treated with siRNA/AD and siRNA/AD/ $\mathrm{E}_{16} \mathrm{G}_{6} \mathrm{RGDK}$. Tissue samples were collected at $24 \mathrm{~h}$ postadministration. No significant histopathological changes were observed in any of the tissue sections. Images were enlarged 200 times with the microscope.

nanoparticles caused any notable hemolytic toxicity at low concentrations. It is noteworthy that the targeted system caused significantly less hemolysis at high concentrations than the nontargeted system (Figure 6E). This finding indicates that coating the positively charged siRNA/AD complexes with the negatively charged $\mathrm{E}_{16} \mathrm{G}_{6} \mathrm{RGDK}$ peptide reduced the hemolytic toxicity. This may be ascribed to the decreased positive surface charge of the peptide-coated delivery system, as revealed by zeta potential measurement and molecular simulations described above.

Furthermore, in healthy mice treated with phosphatebuffered saline (PBS), the targeted delivery system siRNA/ $\mathrm{AD} / \mathrm{E}_{16} \mathrm{G}_{6} \mathrm{RGDK}$ and the nontargeted system siRNA/AD did not cause any signs of discomfort, unusual behavior, or body weight change when delivering the scrambled control siRNA. In addition, mice treated with either the targeted or the nontargeted siRNA/AD systems showed no evidence of induced inflammation, whereas mice treated with the positive control lipopolysaccharide (LPS) exhibited significantly elevated levels of inflammatory factors such as IL-6, INF- $\gamma$, TNF- $\alpha$, GM-CSF, MCP-1, KC, and IL-1 $\beta$ (Figure 7A). Moreover, several major serum biochemistry parameters, including alanine transaminase (ALT), aspartate transaminase (AST), total bilirubin (TBIL), urea, total protein (TP), alkaline phosphatase (ALP), triacylglycerol (TG), and total cholesterol (TCHO), remained at normal levels at $24 \mathrm{~h}$ postadministration, indicating that the main organs, including the liver and kidneys, function well after treatment with these formulations (Figure 7B). Histological analysis of the main organs collected at $24 \mathrm{~h}$ post-treatment revealed that both siRNA/AD and siRNA/AD/ $\mathrm{E}_{16} \mathrm{G}_{6} \mathrm{RGDK}$ were devoid of acute toxicity since no significant pathological change was observed in any of the tissue sections (Figure $7 \mathrm{C}$ ). All these data highlight that the targeted delivery system composed of $\mathrm{AD}$ and $E_{16} G_{6} R G D K$ is safe, as judged by the lack of cytotoxic effects, acute toxicity, or inflammatory responses.

\section{CONCLUSIONS}

In this study, we established a novel system for targeted siRNA delivery based on the amphiphilic dendrimer $\mathrm{AD}$ equipped with the targeting peptide $\mathrm{E}_{16} \mathrm{G}_{6} \mathrm{RGDK}$, which bears the dualtargeting warhead RGDK, the negatively charged oligo(glutamic acid) $\mathrm{E}_{16}$, and the neutral spacer oligo(glycine) $\mathrm{G}_{6}$. This peptide stably coated the positively charged siRNA/AD delivery complexes via electrostatic interaction with its negatively charged $\mathrm{E}_{16}$ segment. The so-formed nanoparticles were small, stable, and able to protect siRNA from degradation. Furthermore, the targeting segment RGDK was accessible for binding to and interacting with the integrin and the neuropilin-1 receptor molecules on the surface of PC-3 prostate cancer cells. This consequently led to specific and enhanced cellular uptake of siRNA followed by effective endosomal escape of the siRNA, which further promoted much stronger gene silencing and resulted in more potent anticancer activity than the nontargeted system in castration-resistant prostate cancer models in vitro and in vivo. In addition, in vitro cytotoxicity, acute in vivo toxicity, and induced in vivo inflammation were not observed for the targeted delivery system. These results indicate the potential of this targeting system for safe and functional siRNA delivery and consequent gene silencing and anticancer activity. This targeting system 
hence holds great promise for treating prostate cancer, in particular castration-resistant prostate cancer, for which there is no efficacious treatment yet.

It is worth mentioning that our amphiphilic dendrimer $\mathrm{AD}$ has been previously demonstrated to deliver siRNA to tumors in xenograft mice for successful gene silencing and anticancer activity. ${ }^{22}$ Those results can mainly be attributed to passive tumor targeting via the enhanced permeation and retention effect in addition to the excellent delivery ability of AD. In this study, we equipped this siRNA delivery system with the dual targeting peptide, further imparting the capacity to specifically target cancer cells for improved gene silencing and hence much more potent anticancer activity at a significantly lower dosage of siRNA. This is the first report to explore a targeting strategy for self-assembling dendrimer-mediated siRNA delivery. Compared with our previous studies using conventional covalent dendrimers, ${ }^{36,52}$ this amphiphilic dendrimer system has similar siRNA loading capacity but more than 10-fold greater potency for in vivo siRNA delivery and consequent antitumor activity. We expect that this approach using a dual targeting peptide to decorate the amphiphilic dendrimer-based

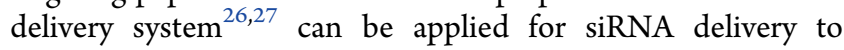
develop RNAi-based personalized medicine against various cancers in general. We are actively working in this direction.

\section{ASSOCIATED CONTENT}

\section{S Supporting Information}

The Supporting Information is available free of charge on the ACS Publications website at DOI: 10.1021 /jacs.8b10021.

Materials and methods as well as all experimental protocols for TEM, DLS, computational details, ITC, cell uptake and endosome release, siRNA delivery, gene silencing, anticancer activity and toxicity, etc. (PDF)

\section{AUTHOR INFORMATION}

\section{Corresponding Authors}

*xiaoxuanliucpu@163.com

*ling.peng@univ-amu.fr

\section{ORCID}

Erik Laurini: 0000-0001-6092-6532

Yuanyu Huang: 0000-0003-3935-7245

Ling Peng: 0000-0003-3990-5248

Notes

The authors declare no competing financial interest.

\section{ACKNOWLEDGMENTS}

Financial support from ARTP (L.P., X.L.), La Ligue Nationale Contre le Cancer (EL2016.LNCC/LPP) (L.P.), and the French National Research Agency under the frame of EuroNanoMed II (ANR-15-ENM2-0006-02, ANR-16-ENM20004-02) (L.P.), National Natural Science Foundation of China (No. 51773227, 81701815) (X.L.), Natural Science Foundation of Jiangsu Province (BK20170735) (X.L.), Recruitment Program for Youth Talents (X.L.), the Program for Jiangsu Province Innovative Research Talents (X.L.), the Program for Jiangsu Province Innovative Research Team (X.L.), the Jiangsu Specially-Appointed Professors Program (X.L.), the Six Talent Peaks Project of Jiangsu Province of China (X.L.), the State Key Laboratory of Natural Medicines at China Pharmaceutical University (SKLNMKF201703, SKLNMZZRC201804) (L.P., X.L.), the Italian Association for Cancer Research (AIRC, IG 17413 to S.P.), Beijing Institute of Technology Research Fund Program for Young Scholars (Y.H.), the Fundamental Research Funds for the Central Universities (Y.H.), the Hunan Provincial Natural Science Foundation of China (2018JJ1019) (Y.H.), and Huxiang Young Talent Program (Y.H.) is gratefully acknowledged. L.D. is supported by the China Scholarship Council and Y.J. by the Fondation de Recherche Médicale (SPF20160936294).

\section{REFERENCES}

(1) Fire, A.; Xu, S.; Montgomery, M.; Kostas, S.; Driver, S.; Mello, C. Potent and specific genetic interference by double-stranded RNA in Caenorhabditis elegans. Nature 1998, 391, 806-811.

(2) Hannon, G. RNA interference. Nature 2002, 418, 244-251.

(3) Castanotto, D.; Rossi, J. The promises and pitfalls of RNAinterference-based therapeutics. Nature 2009, 457, 426-433.

(4) Haussecker, D.; Kay, M. RNA interference. Drugging RNAi. Science 2015, 347, 1069-1070.

(5) Wittrup, A.; Lieberman, J. Knocking down disease: a progress report on siRNA therapeutics. Nat. Rev. Genet. 2015, 16, 543-552.

(6) Ledford, H. Gene-silencing technology gets first drug approval after 20-year wait. Nature 2018, 560, 291-292.

(7) Whitehead, K.; Langer, R.; Anderson, D. Knocking down barriers: advances in siRNA delivery. Nat. Rev. Drug Discovery 2009, 8, 129-138.

(8) Kanasty, R.; Dorkin, J.; Vegas, A.; Anderson, D. Delivery materials for siRNA therapeutics. Nat. Mater. 2013, 12, 967-977.

(9) Yin, H.; Kanasty, R.; Eltoukhy, A.; Vegas, A.; Dorkin, J.; Anderson, D. Non-viral vectors for gene-based therapy. Nat. Rev. Genet. 2014, 15, 541-555.

(10) Juliano, R. The delivery of therapeutic oligonucleotides. Nucleic Acids Res. 2016, 44, 6518-6548.

(11) Pack, D.; Hoffman, A.; Pun, S.; Stayton, P. Design and development of polymers for gene delivery. Nat. Rev. Drug Discovery 2005, 4, 581-593.

(12) Lachelt, U.; Wagner, E. Nucleic acid therapeutics using polyplexes: a journey of 50 years (and beyond). Chem. Rev. 2015, 115, 11043-11078.

(13) Tseng, Y.; Mozumdar, S.; Huang, L. Lipid-based systemic delivery of siRNA. Adv. Drug Delivery Rev. 2009, 61, 721-731.

(14) Wagner, E. Polymers for siRNA delivery: inspired by viruses to be targeted, dynamic, and precise. Acc. Chem. Res. 2012, 45, 10051013.

(15) Wittrup, A.; Ai, A.; Liu, X.; Hamar, P.; Trifonova, R.; Charisse, K.; Manoharan, M.; Kirchhausen, T.; Lieberman, J. Visualizing lipidformulated siRNA release from endosomes and target gene knockdown. Nat. Biotechnol. 2015, 33, 870-876.

(16) Lee, C.; MacKay, J.; Frechet, J.; Szoka, F. Designing dendrimers for biological applications. Nat. Biotechnol. 2005, 23, 1517-1526.

(17) Khandare, J.; Calderon, M.; Dagia, N.; Haag, R. Multifunctional dendritic polymers in nanomedicine: opportunities and challenges. Chem. Soc. Rev. 2012, 41, 2824-2848.

(18) Liu, X.; Rocchi, P.; Peng, L. Dendrimers as non-viral vectors for siRNA delivery. New J. Chem. 2012, 36, 256-263.

(19) Liu, X.; Liu, C.; Catapano, C.; Peng, L.; Zhou, J.; Rocchi, P. Structurally flexible triethanolamine-core poly(amidoamine) dendrimers as effective nanovectors to deliver RNAi-based therapeutics. Biotechnol. Adv. 2014, 32, 844-852.

(20) Reebye, V.; Sætrom, P.; Mintz, P.; Huang, K.; Swiderski, P.; Peng, L.; Liu, C.; Liu, X.; Lindkaer-Jensen, S.; Zacharoulis, D. Novel RNA oligonucleotide improves liver function and inhibits liver carcinogenesis in vivo. Hepatology 2014, 59, 216-227.

(21) Yu, T.; Liu, X.; Bolcato-Bellemin, A.; Wang, Y.; Liu, C.; Erbacher, P.; Qu, F.; Rocchi, P.; Behr, J.; Peng, L. An amphiphilic dendrimer for effective delivery of small interfering RNA and gene silencing in vitro and in vivo. Angew. Chem., Int. Ed. 2012, 51, 84788484. 
(22) Liu, X.; Zhou, J.; Yu, T.; Chen, C.; Cheng, Q.; Sengupta, K.; Huang, Y.; Li, H.; Liu, C.; Wang, Y.; Posocco, P.; Wang, M.; Cui, Q.; Giorgio, S.; Fermeglia, M.; Qu, F.; Pricl, S.; Shi, Y.; Liang, Z.; Rocchi, P.; Rossi, J.; Peng, L. Adaptive amphiphilic dendrimer-based nanoassemblies as robust and versatile siRNA delivery systems. Angew. Chem., Int. Ed. 2014, 53, 11822-11827.

(23) Chen, C.; Posocco, P.; Liu, X.; Cheng, Q.; Laurini, E.; Zhou, J.; Liu, C.; Wang, Y.; Tang, J.; Col, V.; Yu, T.; Giorgio, S.; Fermeglia, M.; Qu, F.; Liang, Z.; Rossi, J.; Liu, M.; Rocchi, P.; Pricl, S.; Peng, L. siRNA delivery: mastering dendrimer self-assembly for efficient siRNA delivery: from conceptual design to in vivo efficient gene silencing. Small 2016, 12, 3667-3676.

(24) Liu, X.; Wang, Y.; Chen, C.; Tintaru, A.; Cao, Y.; Liu, J.; Ziarelli, F.; Tang, J.; Guo, H.; Rosas, R.; Giorgio, S.; Charle, L.; Rocchi, P.; Peng, L. A fluorinated bola-amphiphilic dendrimer for ondemand delivery of siRNA, via specific response to reactive oxygen species. Adv. Funct. Mater. 2016, 26, 8594-8603.

(25) Percec, V.; Wilson, D.; Leowanawat, P.; Wilson, C.; Hughes, A.; Kaucher, M.; Hammer, D.; Levine, D.; Kim, A.; Bates, F. Selfassembly of Janus dendrimers into uniform dendrimersomes and other complex architectures. Science 2010, 328, 1009-1014.

(26) Sherman, S.; Xiao, Q.; Percec, V. Mimicking complex biological membranes and their programmable glycan ligands with dendrimersomes and glycodendrimersomes. Chem. Rev. 2017, 117, 6538-6631.

(27) Bertrand, N.; Wu, J.; Xu, X.; Kamaly, N.; Farokhzad, O. Cancer nanotechnology: the impact of passive and active targeting in the era of modern cancer biology. Adv. Drug Delivery Rev. 2014, 66, 2-25.

(28) Dai, L.; Liu, J.; Luo, Z.; Li, M.; Cai, K. Tumor therapy: targeted drug delivery system. J. Mater. Chem. B 2016, 4, 6758-6772.

(29) Davis, M.; Zuckerman, J.; Choi, C.; Seligson, D.; Tolcher, A.; Alabi, C.; Yen, Y.; Heidel, J.; Ribas, A. Evidence of RNAi in humans from systemically administered siRNA via targeted nanoparticles. Nature 2010, 464, 1067-1070.

(30) Sugahara, K.; Teesalu, T.; Karmali, P.; Kotamraju, V.; Agemy, L.; Greenwald, D.; Ruoslahti, E. Co-administration of a tumorpenetrating peptide enhances the efficacy of cancer drugs. Science 2010, 328, 1031-1035.

(31) Wong, P.; Tang, K.; Coulter, A.; Tan, S.; Baker, J.; Choi, S. Multivalent dendrimer vectors with DNA intercalation motifs for gene delivery. Biomacromolecules 2014, 15, 4134-4415.

(32) Sugahara, K.; Teesalu, T.; Karmali, P.; Kotamraju, V.; Agemy, L.; Girard, O.; Hanahan, D.; Mattrey, R.; Ruoslahti, E. Tissuepenetrating delivery of compounds and nanoparticles into tumors. Cancer Cell 2009, 16, 510-520.

(33) Desgrosellier, J.; Cheresh, D. Integrins in cancer: biological implications and therapeutic opportunities. Nat. Rev. Cancer 2010, 10, 9-22.

(34) Marelli, U.; Rechenmacher, F.; Sobahi, T.; Mas-Moruno, C.; Kessler, H. Tumor targeting via integrin ligands. Front. Oncol. 2013, 3, 222-233.

(35) Teesalu, T.; Sugahara, K.; Kotamraju, V.; Ruoslahti, E. C-end rule peptides mediate neuropilin-1-dependent cell, vascular, and tissue penetration. Proc. Natl. Acad. Sci. U. S. A. 2009, 106, 16157-16162.

(36) Liu, X.; Liu, C.; Chen, C.; Bentobji, M.; Cheillan, F.; Piana, J.; Qu, F.; Rocchi, P.; Peng, L. Targeted delivery of Dicer-substrate siRNAs using a dual targeting peptide decorated dendrimer delivery system. Nanomedicine 2014, 10, 1627-1636.

(37) Svenson, S. The dendrimer paradox-high medical expectations but poor clinical translation. Chem. Soc. Rev. 2015, 46, 4131-4144.

(38) Cao, Y.; Liu, X.; Peng, L. Molecular engineering of dendrimer nanovecters for siRNA delivery and gene silencing. Front. Chem. Sci. Eng. 2017, 11, 663-675.

(39) Zhou, J.; Liu, J.; Cheng, C.; Patel, T.; Weller, C.; Piepmeier, J.; Jiang, Z.; Saltzman, W. Biodegradable poly(amine-co-ester) terpolymers for targeted gene delivery. Nat. Mater. 2012, 11, 82-90.

(40) Grandclement, C.; Borg, C. Neuropilins: a new target for cancer therapy. Cancers 2011, 3, 1899-1928.

(41) Siegel, R.; Miller, K.; Jemal, A. Cancer Statistics, 2017. CaCancer J. Clin. 2017, 67, 7-30.
(42) Grasso, C.; Wu, Y.; Robinson, D.; Cao, X.; Dhanasekaran, S.; Khan, A.; Quist, M.; Jing, X.; Lonigro, R.; Brenner, J.; Asangani, I.; Ateeq, B.; Chun, S.; Siddiqui, J.; Sam, L.; Anstett, M.; Mehra, R.; Prensner, J.; Palanisamy, N.; Ryslik, G.; Vandin, F.; Raphael, B.; Kunju, L.; Rhodes, D.; Pienta, K.; Chinnaiyan, A.; Tomlins, S. The mutational landscape of lethal castration-resistant prostate cancer. Nature 2012, 487, 239-243.

(43) Gundem, G.; Van, P.; Kremeyer, B.; Alexandrov, L.; Tubio, J.; Papaemmanuil, E.; Brewer, D.; Kallio, H.; Hoegnas, G.; Annala, M.; Kivinummi, K.; Goody, V.; Latimer, C.; O’Meara, S.; Dawson, K.; Isaacs, W.; Emmert-Buck, M.; Nykter, M.; Foster, C.; Kote-Jarai, Z.; Easton, D.; Whitaker, H.; Neal, D.; Cooper, C.; Eeles, R.; Visakorpi, T.; Campbell, P.; McDermott, U.; Wedge, D.; Bova, G. The evolutionary history of lethal metastatic prostate cancer. Nature 2015, 520, 353-357.

(44) Lorente, D.; Mateo, J.; Perez-Lopez, R.; de, J.; Attard, G. Sequencing of agents in castration-resistant prostate cancer. Lancet Oncol. 2015, 16, 279-292.

(45) Cornford, P.; Dodson, A.; Parsons, K.; Desmond, A.; Woolfenden, A.; Fordham, M.; Neoptolemos, J.; Ke, Y.; Foster, C. Heat shock protein expression independently predicts clinical outcome in prostate cancer. Cancer Res. 2000, 60, 7099-7105.

(46) Rocchi, P.; So, A.; Kojima, S.; Signaevsky, M.; Beraldi, E.; Fazli, L.; Hurtado-Coll, A.; Yamanaka, K.; Gleave, M. Heat shock protein 27 increases after androgen ablation and plays a cytoprotective role in hormone-refractory prostate cancer. Cancer Res. 2004, 64, 65956602.

(47) Jego, G.; Hazoume, A.; Seigneuric, R.; Garrido, C. Targeting heat shock proteins in cancer. Cancer Lett. 2013, 332, 275-285.

(48) Wei, T.; Chen, C.; Liu, J.; Liu, C.; Posocco, P.; Liu, X.; Cheng, Q.; Huo, S.; Liang, Z.; Fermeglia, M.; Pricl, S.; Liang, X.; Rocchic, P.; Peng, L. Anticancer drug nanomicelles formed by self-assembling amphiphilic dendrimer to combat cancer drug resistance. Proc. Natl. Acad. Sci. U. S. A. 2015, 112, 2978-2983.

(49) Posocco, P.; Liu, X.; Laurini, E.; Marson, D.; Chen, C.; Liu, C.; Fermeglia, M.; Rocchi, P.; Pricl, S.; Peng, L. Impact of siRNA overhangs for dendrimer-mediated siRNA delivery and gene silencing. Mol. Pharmaceutics 2013, 10, 3262-3273.

(50) Albanyan, B.; Laurini, E.; Posocco, P.; Pricl, S.; Smith, D. Selfassembled multivalent (SAMul) polyanion binding-impact of hydrophobic modifications in the micellar core on DNA and heparin binding at the peripheral cationic ligands. Chem. - Eur. J. 2017, 23, 6391-6397.

(51) Fechner, L.; Albanyan, B.; Vieira, V.; Laurini, E.; Posocco, P.; Pricl, S.; Smith, D. Electrostatic binding of polyanions using selfassembled multivalent (SAMul) ligand displays - structure-activity effects on DNA/heparin binding. Chem. Sci. 2016, 7, 4653-4659.

(52) Qi, C.; Su, Y.; Peng, Y.; Tian, E.; Sun, G.; Zhou, J.; Sun, G.; Liu, X.; Chao, C.; Murai, K.; Zhao, C.; Azizian, K.; Yang, L.; Warden, C.; Wu, X.; D’Apuzzo, M.; Brown, C.; Badie, B.; Peng, L.; Riggs, D.; Rossi, J.; Shi, Y. Downregulation of TLX induces TET3 expression and inhibits glioblastoma stem cell self-renewal and tumorigenesis. Nat. Commun. 2016, 7, 10637-10651. 